\title{
L'identité politique de Lyon. Entre violences collectives et mémoire des élites (1786-1905)
}

\section{Bernard Gainot}

\section{(2) OpenEdition \\ 1 Journals}

\section{Édition électronique}

URL : https://journals.openedition.org/ahrf/1079

DOI : 10.4000/ahrf.1079

ISSN : 1952-403X

Éditeur :

Armand Colin, Société des études robespierristes

\section{Édition imprimée}

Date de publication : 1 mars 2001

Pagination : 146-148

ISSN : 0003-4436

\section{Référence électronique}

Bernard Gainot, «L'identité politique de Lyon. Entre violences collectives et mémoire des élites

(1786-1905) ", Annales historiques de la Révolution française [En ligne], 323 I janvier-mars 2001, mis en ligne le 10 avril 2006, consulté le 24 avril 2022. URL : http://journals.openedition.org/ahrf/1079 ; DOI : https://doi.org/10.4000/ahrf.1079

Ce document a été généré automatiquement le 24 avril 2022.

Tous droits réservés 


\title{
L'identité politique de Lyon. Entre violences collectives et mémoire des élites (1786-1905)
}

\author{
Bernard Gainot
}

\section{RÉFÉRENCE}

Bruno Benoît, L'identité politique de Lyon. Entre violences collectives et mémoire des élites (1786-1905), préface de Maurice Garden. L'harmattan, 1999, collection «Chemins de la mémoire», $212 \mathrm{p}$ + index des noms de personnes associées à l'histoire de Lyon de 1786 à 1905.

1 Cet ouvrage est le produit des nombreuses recherches de l'auteur sur les «représentations» du passé lyonnais véhiculées à l'occasion de divers événements récents et commémorations, parmi lesquels le bicentenaire de la Révolution tient une place éminente.

2 À l'exemple de ce qui s'est produit en Vendée, la population lyonnaise a connu un traumatisme majeur dans le cours de son développement historique: le soulèvement sectionnaire du 29 mai 1793, suivi de l'épisode fédéraliste et du siège pendant l'été. Mais le propos de l'ouvrage n'est pas de présenter un récit chronologique; le rappel des faits dans la première partie, bref mais indispensable, permet d'insister sur la présence récurrente de la violence collective, depuis les émeutes artisanales sur les tarifs de la Fabrique (la révolte des deux sous de 1786) jusqu'à l'assasinat du président Sadi Carnot place des Cordeliers, le 24 juin 1894, en passant par les mouvements libéraux de 1814-1817, de 1831, de 1834, l'organisation démocratique des Voraces sous la Seconde République, les Internationalistes libertaires de la Commune, etc. Mais l'événement emblématique, la référence majeure, c'est 1793, «événement fondateur, traumatisant, mais aussi émancipateur et identitaire» (p.80). 
3 La mémoire de ces violences collectives, généralement associées à de puissants mouvements sociaux, est l'objet d'une construction politique au cours du xIx ${ }^{e}$ siècle. Les étapes de la «construction mémorielle» sont retracées dans la deuxième partie, ainsi que les vecteurs (textes, armoiries, mythes historiques, historiographie locale) à partir desquels elle s'organise. Les acteurs de cette construction appartiennent à une bourgeoisie locale d'ancienne extraction, de sensibilité modérée, fondamentalement marquée par le péril rouge, mais aussi plus subtilement par la crainte des débordements contre-révolutionnaires, auxquels peut donner lieu la peur sociale, autorisant ainsi la pesante tutelle du pouvoir central.

Bruno Benoît présente dans une troisième partie les contradictions qui parcourent ces «élites libérales» au début du XIX ${ }^{e}$ siècle, dès lors qu'il s'agit de proposer une clef de lecture des événements récents; «la mémoire des élites libérales a mis en place un scénario catostrophe, réactualisé à chaque explosion de violences collectives, où la guerre civile le dispute à la ruine matérielle de la ville» (p. 151). Les «élites» sont effectivement longtemps partagées entre leur répugnance pour la République, généralement associée au souvenir des «chaliers» et de la présence montagnarde de 1793-1794, et leur méfiance envers le royalisme volontiers assimilé aux excès de la terreur blanche, prompt à se manifester dans les périodes de réaction. La difficile synthèse, réalisée grâce à la fusion progressive entre des républicains modérés et des libéraux très influencés par les évolutions du catholicisme, s'opère sous la Troisième République, avec l'accession d'Édouard Herriot aux responsabilités municipales. Mais ladite «synthèse herriotiste» (p. 163) a été préparée par une «construction mémorielle», qui ordonne les lectures historiques autour d'une identité collective lyonnaise. Les marqueurs d'identité les plus fréquents sont le modérantisme, le rejet de la centralisation, l'attachement à l'autonomie municipale.

5 Ainsi, pour nous en tenir à la période révolutionnaire, le personnage de Chalier, très présent dans la mémoire lyonnaise, emprunte-t-il nombre de ses traits négatifs au fait qu'il soit un «homme nouveau», originaire du Piémont. La lutte acharnée entre les armées de la Convention et les fédéralistes lyonnais prend l'aspect du combat séculaire pour la défense des libertés locales étouffées par le centralisme parisien. Pourtant, l'aspect proprement militaire, l'importance stratégique de la place de Lyon, le boulevard du Midi (vu de Paris) est-il constamment mis en avant par les autorités, quelle que soit la période d'ailleurs: le maréchal de Castellane le rappelle encore sous le Second Empire; «Lyon exerce une immense influence sur le Midi de la France. Le maintien de la tranquillité dans cette cité est donc chose importante pour le gouvernement...» (p. 73)

6 La notoriété et la longévité d'Herriot sont largement fondées sur le récit historique classique des événements révolutionnaires, symboliquement intitulé Lyon n'est plus. Pour que Lyon existe, il est donc essentiel de dégager un consensus autour de l'autonomie locale et de la république modérée, rejetant aussi bien Chalier, archétype de tous les révolutionnaires sociaux, que Précy, archétype de la récupération royaliste ultra.

7 Quant à la cohésion et à la durée de cette synthèse centriste, il faudrait s'interroger plus longuement sur les héritages du $\mathrm{xx}^{\mathrm{e}}$ siècle, des débats parfois animés autour de la commémoration de 1989, jusqu'aux emprunts faits par l'actuel maire de Lyon à ladite synthèse pour en proposer la version démocrate-chrétienne.

8 L'auteur insiste, à juste titre, sur l'originalité de cette construction mémorielle autour d'un événement fondateur; ni Bordeaux, ni Marseille, selon lui, n'ont connu semblable 
rupture, en dépit des similitudes de 1793. La grande ville qui serait alors la plus proche de Lyon est Rouen, mais la construction d'une mémoire et d'une identité n'y a pas été aussi poussée que dans l'ancienne métropole des Gaules.

$9 \mathrm{Au}$ terme de cette démonstration rigoureuse et convaincante, des interrogations subsistent néanmoins. Tout d'abord sur le lien entre identité politique et identité sociale; Bruno Benoît rappelle les évolutions économiques qui font éclater le cadre de la fabrique, au cours du xIX $x^{e}$ siècle. Mais, tout comme le canut cède la place au prolétaire, on peut s'interroger sur la permanence des «élites libérales» tout au long de la période. Le consensus se construit en fait à un moment où s'estompent les formes violentes prises par les rapports sociaux lorsque la fabrique était prédominante. L'identité politique ne se définit-elle pas en occultant une autre mémoire, toute aussi présente dans cette ville qui fut la «ville sainte du socialisme»(p.78)? La figure de Chalier n'occulte-t-elle pas celle de réformateurs sociaux, comme Lange, dont Jaurès soulignait toute la grandeur et l'originalité dans son Histoire socialiste publiée alors même que triomphait la «synthèse herriotiste»?

10 Une autre grande question, fort complexe, est celle du rapport entre le lien national et le lien local. Il y a par exemple ce que le fédéralisme a pu représenter à l'époque même, en 1793, et la relecture qui en a été faite par un régionalisme conservateur au XIX siècle. D'importantes recherches récentes ont été menées sur le premier aspect, et singulièrement sur les liens avec le jacobinisme. Aussi l'emploi systématique d'expressions comme la «convention jacobino-montagnarde» (p. 36), les «jacobinochaliéristes» (p.38), la «Convention républicano-parisienne» (p. 179), ne contribue guère à la clarification de cette question, d'autant plus qu'elles contredisent la démarche de l'auteur qui montre que ce rejet du jacobinisme n'était pas partagé par l'ensemble de la population lyonnaise, et qu'il participe largement à la Constitution des mythes identitaires.

11 Les dix-sept pages de la bibliographie, très riche, très maîtrisée, permettent à tous ceux qu'intéresse le développement du mouvement révolutionnaire lyonnais, sa grande singularité par rapport aux autres villes majeures de France, d'approfondir ces questions. 